\title{
Optimization and Validation of Analytical Method for Determination of Some Organic Disinfectants in Some Agricultural Products
}

\author{
Maher A. EL-Hashash ${ }^{1}$, Mohamed El Sayed Amer ${ }^{2}$, Osama El. Hussein ${ }^{2}$ and Mostafa M. H. Khali1 ${ }^{1 *}$ \\ ${ }^{1}$ Department of Chemistry, Faculty of Science, Ain Shams University, Cairo, 11566, Egypt, \\ ${ }^{2}$ Central Laboratory of Residue Analysis of Pesticides and Heavy Metals in Food (QCAP), Agricultural Research Center \\ (ARC), Ministry of Agriculture and Land Reclamation, Dokki, Giza, 12311, Egypt.
}

ARTICLE INFO

Article history:

Received 05 April 2017

Accepted 08 May 2017

Keywords:

QACs;

LC-MS/MS;

Validation.

\begin{abstract}
A B S T R A C T
In the present study, simple and reliable method for the analysis of some quaternary ammonium compounds (QACs) was developed, optimized and validated to meet the requirements of some agricultural products (green beans, orange and olive) safety. QACs in samples were extracted with acetonitrile and identified by liquid chromatography tandem mass spectrometry (LC-MS/MS) with gradient mobile phase $(10 \mathrm{mM}$ ammonium formate solution in methanol/water (1:9)) and $\mathrm{pH} 4 \pm 0.1$. The method was validated with average recovery ranged from 78 to $117 \%$ and coefficient of variation (CV \%) less than $10 \%$. The performance of the proposed method was checked with two samples from the Food Analysis Performance Assessment Scheme (FAPAS) as an external quality control; the $\mathrm{Z}$-score $(\mathrm{Z})$ was found within acceptable range $|Z| \leq 2$. The measurement uncertainty is expressed as expanded uncertainty and in terms of relative standard deviation (at $95 \%$ confidence level) is $\pm 19 \%$. This method is suitable for laboratories engaged daily in routine analysis of a large number of samples.
\end{abstract}

\section{Introduction}

Some quaternary ammonium compounds (QACs) containing at least one long alkyl chain have biocidal properties and are widely used as general fabric softeners, disinfectants, preservatives, pest-control and anti-fouling products. Quaternary ammonium compounds (QACs) are frequently leaked into surface waters from waste water treatment plants, disturbing the ecological balance due to their toxicity to aquatic environment ${ }^{[1]}$.

Their fate in the environment is of concern since there is a lack of data on their degradation ${ }^{[2]}$. Some of them are known to be toxic even at low concentrations ${ }^{[3]}$. The Biocidal Products Directive (BPD) aims to establish a single European market for biocides and to ensure that protection is provided for users, as well as, for the public and the environment.

Benzalkonium chloride (BAC) is a mixture of alkylbenzyldimethylammonium chlorides in which the alkyl groups have a chain length from C8 to $\mathrm{C} 18^{[4]}$. This mixture is widely used as an active substance in anti-bacterial and anti-fungal products, in preservatives, medical disinfectants and ophthalmic systems ${ }^{[5]}$.

\footnotetext{
* Corresponding author.

E-mail address: Khali162@yahoo.com
}

The most commonly used homologues are C12-BAC, C14-BAC and C16-BAC. Each homologue possesses different physical, chemical and biocidal properties. In general, the C12-BAC homologue is most effective against yeast and fungi, the C14-BAC homologue against gram-positive bacteria, and the C16-BAC homologue against gram-negative bacteria ${ }^{[6]}$.

Other quaternary ammonium compounds, such as dialkyldimethylammonium compounds, are also commonly used as biocides and some manufacturers of hospital disinfectant products have substituted BAC with didecyldimethylammonium chloride (DDAC) ${ }^{[6]}$.

$\mathrm{BAC}$ is not an approved active substance in plant protection products under Regulation (EC) No $1107 / 2009$ of the European Parliament and of the Council 21 October 2009 concerning the placing of plant protection products on the market and repealing Council Directives 79/117/EEC and 91/414/EEC/2009.

DDAC was approved as an active substance in plant protection products for use on ornamental crops, but all authorizations for plant protection products containing DDAC have been revoked following the withdrawal of the approval Commission Implementing Regulation (EU) No 175/2013 of 27 February 2013 amending Implementing Regulation (EU) No 540/2011. As regards 


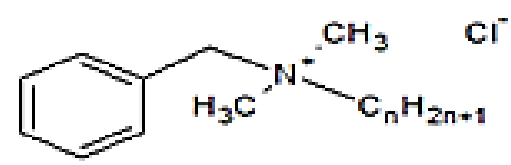

a)

$n=8,10,12,14,16,18$

b)

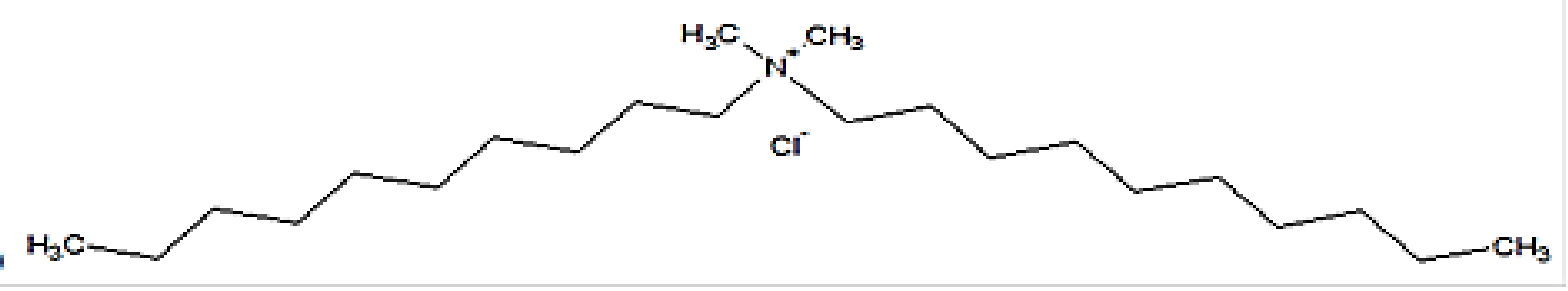

(a) Benzalkonium chloride (BAC) with chain length of $n=10,12,14,16$.

(b) Didecyldimethylammonium chloride (DDAC).

the withdrawal of the approval of the active substance didecyldimethylammonium chloride, both substances are used as biocides for disinfection that use may lead to detectable residues in food. The monitoring data was collected in 2012 and 2013 by Member States and food business operators and showed that those substances are present at levels that vary depending on the source and product, but that the levels frequently exceed the default maximum residue limit (MRL) of $0.01 \mathrm{mg} / \mathrm{kg}^{[7]}$.

These findings provide evidence of the unavoidable presence of BAC and DDAC in or on certain products. Several analytical methods for the determination of QACs in foods have been described. These include the use of Liquid chromatography/electrospray/ion trap tandem mass spectrometry equipped with a reversedphase C18 analytical column (Phenomenex RP18, Torrance, CA) of $250 \times 3 \mathrm{~mm}$ and $5 \mu \mathrm{m}$ particle diameter in identification of QACs surfactants in water samples ${ }^{[8,9]}$ Another analytical column in LC-MS/MS which is called Waters Spherisorb CN, (4.6x250 mm) column packed with particles of $5 \mu \mathrm{m}$ applied for the determination of BAC in a pharmaceutical formulation of latanoprost ophthalmic solution ${ }^{[10]}$, UV-visible spectrometry using silver nitrate and eosin solution was used in the determination of BAC after formulation [11,12]. Of these techniques, HPLC is the most frequently reported for the separation and quantification of QACs because of its high sensitivity and wide range of linearity.

The objective of this study is to establish a rapid, sensitive, and reproducible analytical method for quantification of QACs in green beans, orange's fruit and olive's fruit to access their compliance to the established standards before consuming locally or exporting to other countries. The developed method will be validated in terms of sensitivity, repeatability, linearity, accuracy and precision. The applicability of the developed method for the routine monitoring of locally produced or exported agricultural products will be investigated, as part of the National Monitoring Program for food contaminates in Egyptian food. This should help various Egyptian exporters to penetrate international markets.

\section{Materials and methods}

\section{Samples collection and processing}

Green beans, orange's fruit and olive's fruit samples purchased from local markets in Egypt during the years 2014-2016 and analyzed using the developed method. Samples were immediately frozen during transport and kept at $-20{ }^{\circ} \mathrm{C}$ not more than two days till sample treatment and analysis. Before analysis, samples were homogenized well and taken for analysis. Preparation and sampling was performed according to guidelines of codex alimentarius commission ${ }^{[13]}$.

\section{Chemicals, reagents and standard solutions}

Five QACs reference standard active ingredients of Benzalkonium chloride (BAC10), (BAC12), (BAC14), (BAC16) and Didecyldimethylammonium chloride (DDAC) were purchased from Sigma-Aldrich with purity $>98 \%$.

Acetonitrile and Methanol (Lab-scan) (HPLC), assay > 99\%., De-ionized Water generated by Milli-Q,Agilent QuEChERs salts and buffers were prepackaged in anhydrous packages for EN 15662 containing $4 \mathrm{~g}$ magnesium sulfate $\left(\mathrm{MgSO}_{4}\right), 1 \mathrm{~g}$ sodium chloride $(\mathrm{NaCl}), 1 \mathrm{~g}$ trisodium citrate dihydrate, and $0.5 \mathrm{~g}$ disodium citrate sesquihydrate. Formic acid, 98-100\% (Riedel-de Haen), ammonia solution, 33\% (Riedel-de Haen). HPLC mobile Phase Stock solution (50 mM ammonium formate solution in methanol/water (1:9) was prepared by adding $1.73 \mathrm{ml}$ formic acid to $900 \mathrm{ml}$ water, adjust the $\mathrm{pH}$ to about $3.78 \pm 0.02$ with ammonia solution (30\%) and then addition of $100 \mathrm{ml}$ methanol). HPLC mobile Phase working solution (10 $\mathrm{mM}$ ammonium formate solution in methanol/water (1:9) was prepared by diluting $200 \mathrm{ml}$ of HPLC mobile phase stock solution with $800 \mathrm{ml}$ methanol/water (1:9)). The $\mathrm{pH}$ should be $4 \pm 0.1$.

QACs Stock solution $(1000 \mu \mathrm{g} / \mathrm{ml})$ in methanol was prepared and kept at $-20 \pm 2{ }^{\circ} \mathrm{C}$ not longer than one year. Intermediate solution $(100 \mu \mathrm{g} / \mathrm{ml})$ was prepared in acetonitrile and stored at $4 \pm 2{ }^{\circ} \mathrm{C}$ not longer than 6 months. 
A series of calibration solutions of $0.001,0.002,0.005$, $0.01, \quad 0.05$ and $0.1 \mu \mathrm{g} / \mathrm{ml}$ were prepared from intermediate standard solution $(100 \mu \mathrm{g} / \mathrm{ml})$ by serial dilution in $10 \mathrm{ml}$ flask. The calibration solutions were kept also at $4 \pm 2^{\circ} \mathrm{C}$. This calibration solutions will be used up to three months.

\section{Apparatus and chromatographic conditions}

Acrodisc ${ }^{\circledR}$ syringe filters PTFE

(Polytetrafluoroethylene), diam. $25 \mathrm{~mm}$, pore size 0.45 $\mu \mathrm{m}$, Polypropylene Centrifuge Tubes with Screw Caps 15 and $50 \mathrm{ml}$.

Lab Centrifuge (Heraeus Labofuge 400) capable of achieving at least $4000 \mathrm{rpm}$.

Injection Vials $(1.5 \mathrm{ml})$ suitable for LC-MS/MS auto sampler, Screw capped glass vials $(20 \mathrm{ml})$ for the storage of the excessive amounts of the final extract. Volumetric Flasks, Grade A 10, 25, 50, and $100 \mathrm{ml}$. Automatic Pipettes, Hirschman Labogerate suitable for handling volumes of $10 \mu \mathrm{l}$ to $100 \mu \mathrm{l}$, and $100 \mu \mathrm{l}$ to 1000 $\mu 1$. Analytical balance, Mettler Toledo AG 204: range from $0.1 \mathrm{mg}$ to $210 \mathrm{gm}$. Precision balance, Mettler Toledo GG 4002-S: Delta range from $0.5 \mathrm{gm}$. to 4100 gm. pH-meter, Thermo Electron Orion Star pH Bench Top.

Quantitative analysis was performed using the high performance liquid chromatography HLPC Agilent system, HP 1100 series equipped with binary pump (G1311A), Vacuum degasser (G1322), Auto sampler (G1313). HPLC equipped with fluorescence detector Agilent 1100 series (G1321A) and triple Quadruple mass spectrometer (ABSCIEX). Separation performed on Agilent Zorbax XDB C18, 5um $\times 150 \times 4.6 \mathrm{~mm}$ column. Software: Chemistation for LC, Rev. A. 09.03.

The flow rate of HPLC pump was $0.3 \mathrm{ml} / \mathrm{min}$. The elution condition involves using a gradient mode and mobile phase (B) of methanol and mobile phase (A) of $10 \mathrm{mM}$ ammonium formate solution in methanol/water (1:9), the $\mathrm{pH}$ should be $4 \pm 0.1$; the injection volume was $5 \mu 1$.

\section{Method of analysis}

\section{Preparation of samples for QACs extraction}

A test portion of $10 \mathrm{~g}$ homogenized sample (green beans, orange's fruit and olive's fruit) was weighed in 50 $\mathrm{ml}$ plastic tube, $10 \mathrm{ml}$ acetonitrile was added and shaked well for one minute by hand then the buffer-salt-mixture was added and shaked immediately for three minutes. The sample was centrifuged at $4000 \mathrm{rpm}$ for 5 minutes. Portion of acetonitrile layer was filtrated using Acrodisc and injected directly $5 \mu 1$ into LC-MS/MS system.

Reagent blank (solvent and reagent) and blank sample (free QACs sample) were analyzed with each set of samples.

Calibration standard curve was used for the quantification of QACs in samples (peak height VS standard concentration).

\section{Calculations:}

The QACs concentration in sample Cs $(\mathrm{mg} / \mathrm{kg})$ was calculated as follows:

$$
C s=\frac{V_{f}}{w} \times \frac{h \mathrm{sam}}{h s t d} \times y
$$

$C s=$ sample concentration $(\mu \mathrm{g} / \mathrm{g})$,

$V f=$ final volume $(\mathrm{ml})$,

hsam $=$ the height of sample peak,

$h s t d=$ the height of standard in matrix peak,

$Y=$ standard concentration $(\mu \mathrm{g} / \mathrm{ml})$,

$W=$ weight of sample $(\mathrm{g})$.

\section{Validation and Quality Assurance}

The analytical method and instrument were fully validated as part of the quality assurance system in Central Lab. Of Residue Analysis of Pesticides and Heavy Metals in Food and accredited by FINAS, Center for Metrology and Accreditation - Finland, according to (ISO/ IEC 17025, 2005). The criteria of quality assurance of Codex Committee were followed to determine the performance of the analytical method. Validation of the method included; recovery percentages, precision, accuracy, limits of quantification and uncertainty of measurements were carried out for QACs using green beans, orange's fruit and olive's fruit samples in accordance with the international guidelines.

\section{Results and discussion}

\section{Method development}

The published method ${ }^{[14]}$ which is applied for the determination of pesticide residues using GC-MS and/or LC-MS/MS following acetonitrile extraction/partitioning and cleanup by dispersive solid phase extraction (SPE) was selected to be developed and optimized to determine QACs in some agricultural products.

Modifications to standard method are optional evaporation step of acetonitrile and re-dissolve in methanol/water (1:1) before LC-MS/MS analysis, adding $5 \%$ formic acid to acetonitrile extract, mobile phase in standard method was ammonium formate solution in water, concentration $=5 \mathrm{mmol} / \mathrm{l}$, ammonium formate solution in methanol, concentration $=5 \mathrm{mmol} / \mathrm{l}$, use Phenomenex C18 column and flow rate is $0.4(\mathrm{ml} / \mathrm{min})$.

\section{HPLC separation conditions}

Table (1) summarizes gradient HPLC mobile phase (10 $\mathrm{mM}$ ammonium formate solution in methanol/water (1:9)). The $\mathrm{pH}$ was adjusted at $4 \pm 0.1$ with flow rate $0.3 \mathrm{ml} / \mathrm{min}$ and Figure (1) shows the ratio of the solvents (A) and (B) during time of analysis.

\section{MS/MS parameters of 5 QACs:-}

Table (2) shows that MS/MS parameters of 5 QACs where Q1 and Q3 are masses $(\mathrm{m} / \mathrm{z})$ of daughter ions fragments in dalton, declustering potential (DP), entrance potential (EP) and collision cell entrance potential are pre-collision cell voltages.

The EP parameter controls the entrance potential, which guides and focuses the ions through the high-pressure Q0 region. The CXP is the exit potential of collision cell.

The CE (collision cell entrance potential) parameter controls the potential difference between Q0 and Q2 (collision cell). It is used only in MS/MS-type scans. 
The CE is the amount of energy that the precursor ions receive as they are accelerated into the collision cell, where they collide with gas molecules and fragment.
Figure (2) shows the total ion chromatogram of QACs and Figure (3) shows the masses $(\mathrm{m} / \mathrm{z})$ of daughter ions fragments in Dalton of QACs.

Table (1): HPLC pump settings

\begin{tabular}{|c|c|c|c|c|}
\hline Step & Total Time (min) & Flow Rate $(\mathbf{m l} / \mathbf{m i n})$ & $\begin{array}{c}\text { A } \\
(\mathbf{\%})\end{array}$ & $\begin{array}{c}\text { B } \\
(\boldsymbol{\%})\end{array}$ \\
\hline $\mathbf{0}$ & 0.00 & 0.3 & 100.0 & 0.0 \\
\hline $\mathbf{1}$ & 13.00 & 0.3 & 5.0 & 95.0 \\
\hline $\mathbf{2}$ & 21.00 & 0.3 & 5.0 & 95.0 \\
\hline $\mathbf{3}$ & 22.20 & 0.3 & 100.0 & 0.0 \\
\hline $\mathbf{4}$ & 25.00 & 0.3 & 100.0 & 0.0 \\
\hline
\end{tabular}

B: pure methanol, $\mathbf{A}: 10 \mathrm{mM}$ ammonium formate solution in methanol/water (1:9), the $\mathrm{pH}$ should be $4 \pm 0.1$. Temperature of column is $40^{\circ} \mathrm{C}$.

Table (2): MS/MS parameters of five QACs.

\begin{tabular}{|c|c|c|c|c|c|c|}
\hline Q1 MASS & Q3MASS & ID & DP & EP & CE & CXP \\
\hline 326.4 & 186.2 & DAC_326.4_186.2 & 140 & 10 & 40.3 & 8 \\
\hline 326.4 & 43.2 & DAC_326.4_43.2 & 140 & 10 & 68.7 & 8 \\
\hline 326.4 & 41.2 & DAC_326.4_41.2 & 140 & 10 & 98 & 8 \\
\hline 360 & 91 & BAC16_360_91 & 101 & 10 & 67 & 14 \\
\hline 360 & 268 & BAC16_360_268 & 101 & 10 & 35 & 14 \\
\hline 304 & 91 & BAC12_304_91 & 106 & 10 & 55 & 14 \\
\hline 304 & 212 & BAC12_304_212 & 101 & 10 & 31 & 10 \\
\hline 332.3 & 91 & BAC14_332.3_91 & 106 & 10 & 73 & 14 \\
\hline 332.3 & 240.3 & BAC14_332.3_240.3 & 116 & 10 & 33 & 12 \\
\hline 276 & 184 & BAC_10_276_184 & 101 & 10 & 25 & 27 \\
\hline 276 & 91 & BAC_10_276_91 & 96 & 10 & 75 & 43 \\
\hline
\end{tabular}

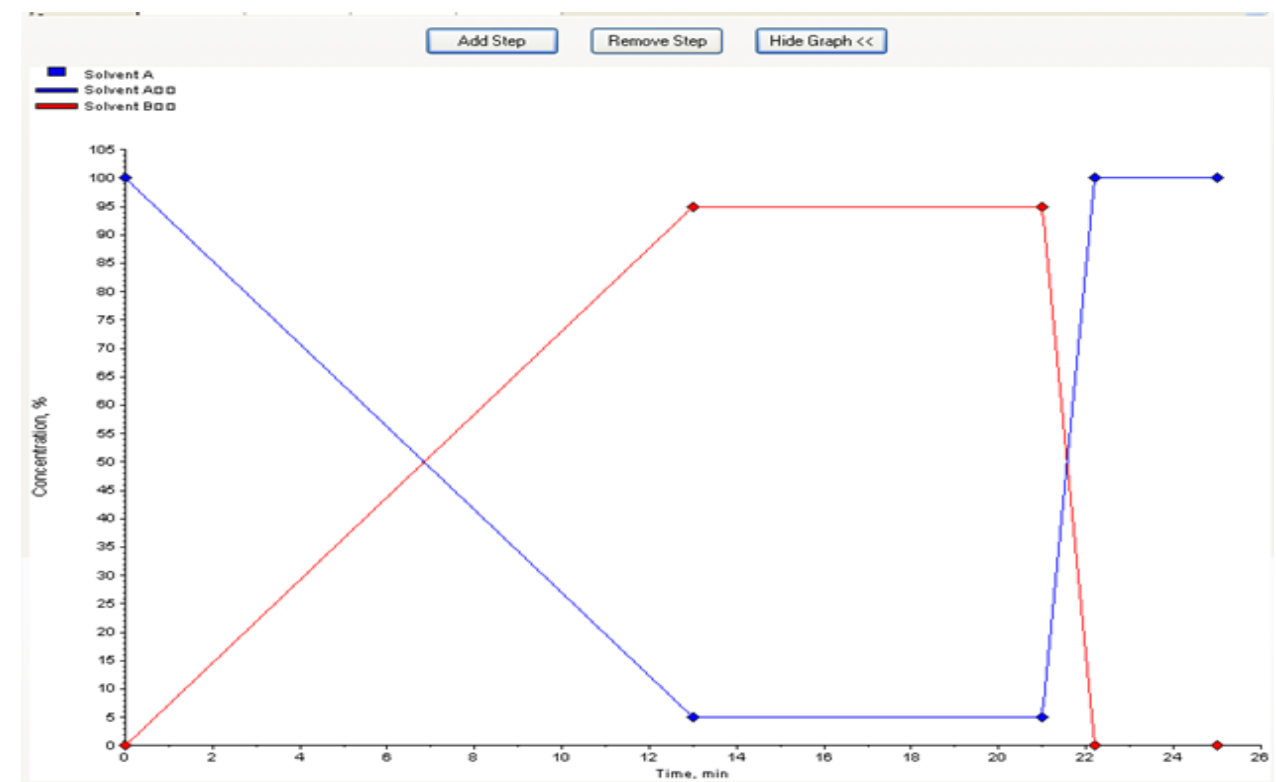

Fig. 1: The ratio of solvents (A) and (B) during time of analysis. B: pure methanol, $\mathbf{A}: 10 \mathrm{mM}$ ammonium formate solution in methanol/water (1:9), the $\mathrm{pH}$ should be $4 \pm 0.1$. Temperature of column is $40^{\circ} \mathrm{C}$. 


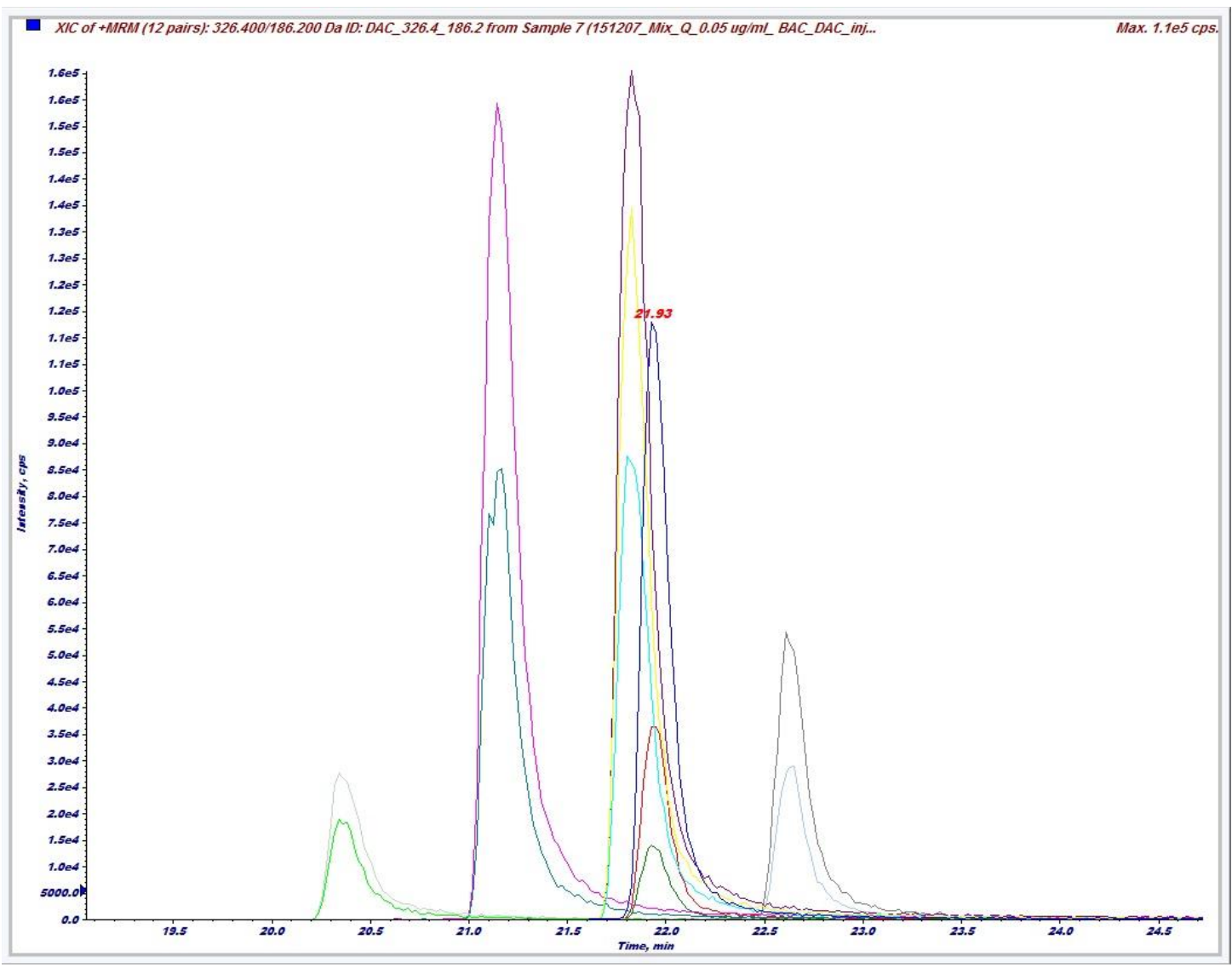

Fig. 2: The Ion chromatogram of QACs.

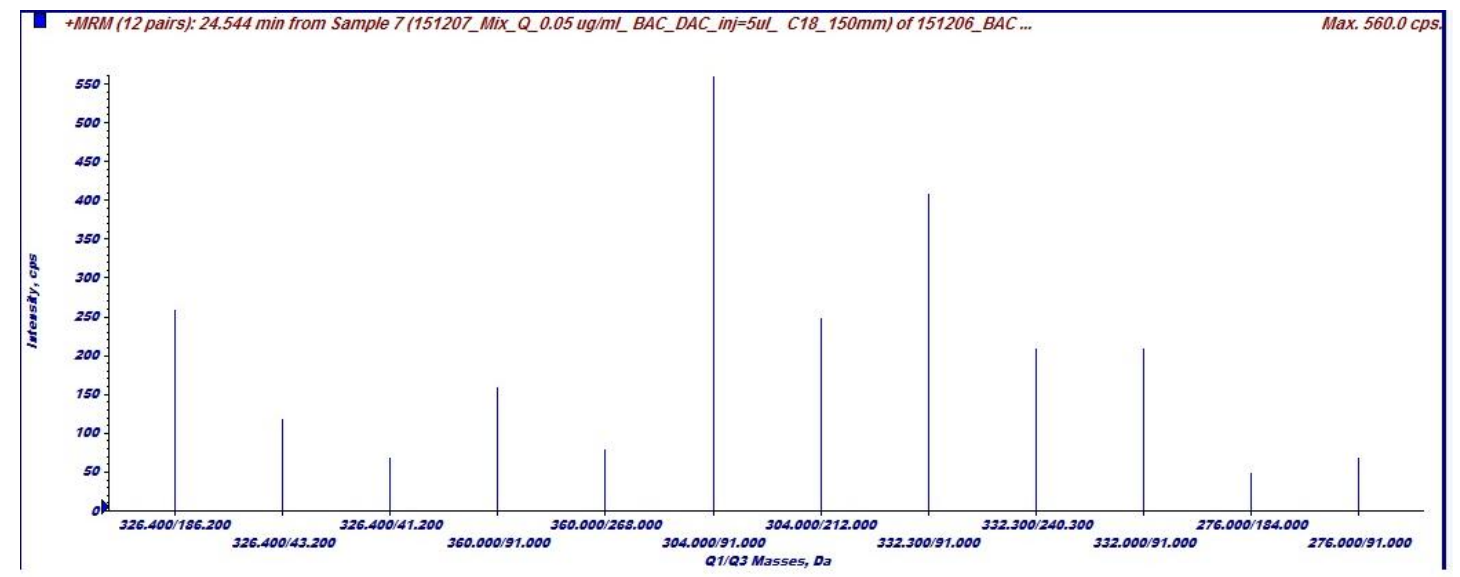

Fig. 3: The Masses $(\mathrm{m} / \mathrm{z})$ of daughter ions fragments in dalton of QACs.

\section{Method validation}

After method development and optimization of different parameters, the method must be tested to prove the "Fitness for Purpose" through a process called method validation. Many international standards were published to discuss different method validation parameters; ${ }^{[15-17]}$ were followed in performing the different validation parameters and uncertainty estimation. The obtained validation results described are as follows. Validation of analysis included linearity, limit of detection (LOD), limit of quantification (LOQ), recovery, precision (repeatability and reproducibility) and accuracy.

\section{Linear range and calibration curve}

Six calibration levels of $0.001,0.002,0.005,0.01,0.05$ and $0.1 \mu \mathrm{g} / \mathrm{ml}$ usually used for calibration. A linear curve was found between peak area and analyte concentration with a good correlation coefficient $\left(R^{2} \geq 0.999\right)$. Calibration was done with each set of injected samples; the linear calibration curves are illustrated in Figures 4 \& 5 .

Method linearity was tested by performing recovery tests at different three levels of $0.01,0.05$ and $0.1 \mathrm{mg} / \mathrm{kg}$ on green beans, orange and olive samples. The method was found to be linear from the limit of quantitation $0.01 \mathrm{mg} / \mathrm{kg}$ 
up to $0.1 \mathrm{mg} / \mathrm{kg}$ with correlation coefficient 0.999 .

Table (3) summarizes regression coefficient (r) that represents the linearity of the calibration curve and also regression equation and obtained for calibration.

\section{Recovery tests}

The recovery tests using six replicates at three concentration levels and relative standard deviation $(\mathrm{RSD} \%=\mathrm{CV} \%)$ were calculated according to the following equation ${ }^{[18]}$ :

$$
R S d \%=\frac{S}{\bar{x}} \times 100
$$

where,

RSd \% = Relative standard deviation,

$\mathrm{S}=$ Standard deviation,

$\bar{x}=$ Mean of found concentration in n samples.

Recovery was calculated using the following equation:

$$
\text { Recovery } \%=\frac{C_{f}}{C_{e}} \times 100
$$

Where,

$\mathrm{Cf}=$ Found concentration, $\mathrm{Ce}=$ Added concentration .
The results in Table (4) show that the QACs could be determined with accepted recovery and precision using modified QuEChERS method of analysis for extraction, and LC-MS/MS for quantification.

For green beans samples, the recovery of each set of six replicates was in the range of $80-98 \%$, where the lower spiking level was selected in order to include the lower concentration of QACs green beans fixed at $0.01 \mathrm{mg} / \mathrm{kg}$.

For orange samples, the recovery of each set of six replicates was in the range of $94-107 \%$, while for olive record $80-100 \%$.

\section{Limit of detection (LOD)}

The limit of detection calculated as approximately three times the standard deviation of each compound for green beans, orange and olive as shown in Table (5).

The results in Table (5) show that, LODs for green beans ranged from $0.001 \mathrm{mg} / \mathrm{kg}$ for BAC16 and BAC12 to $0.003 \mathrm{mg} / \mathrm{kg}$ for DDAC and $\mathrm{BAC} 14$, while for orange the LODs ranged from $0.001 \mathrm{mg} / \mathrm{kg}$ for BAC10 to 0.004 $\mathrm{mg} / \mathrm{kg}$ for BAC12.

LODs for olive ranged from $0.002 \mathrm{mg} / \mathrm{kg}$ for DDAC, $\mathrm{BAC} 10$ and $\mathrm{BAC} 16$ to $0.003 \mathrm{mg} / \mathrm{kg}$ for $\mathrm{BAC} 14$ and BAC12.

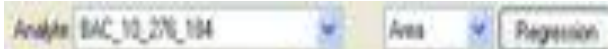

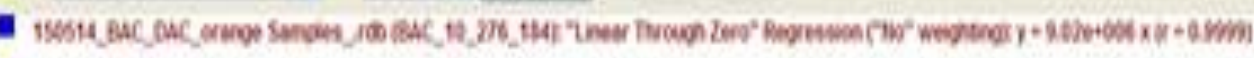

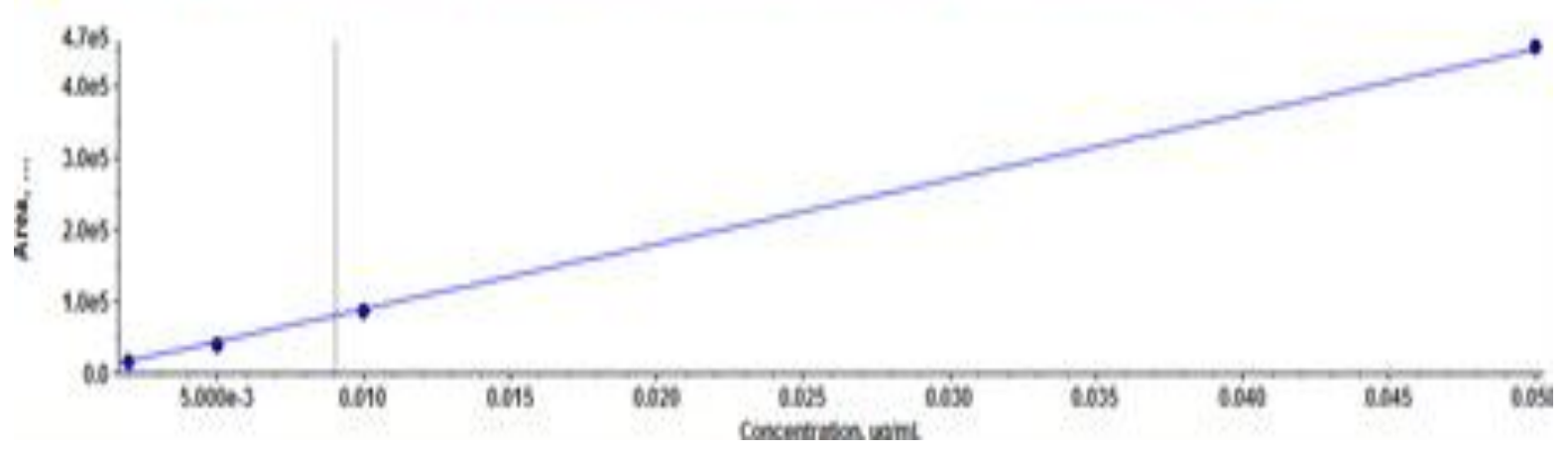

Fig. 4: BAC calibration curve.

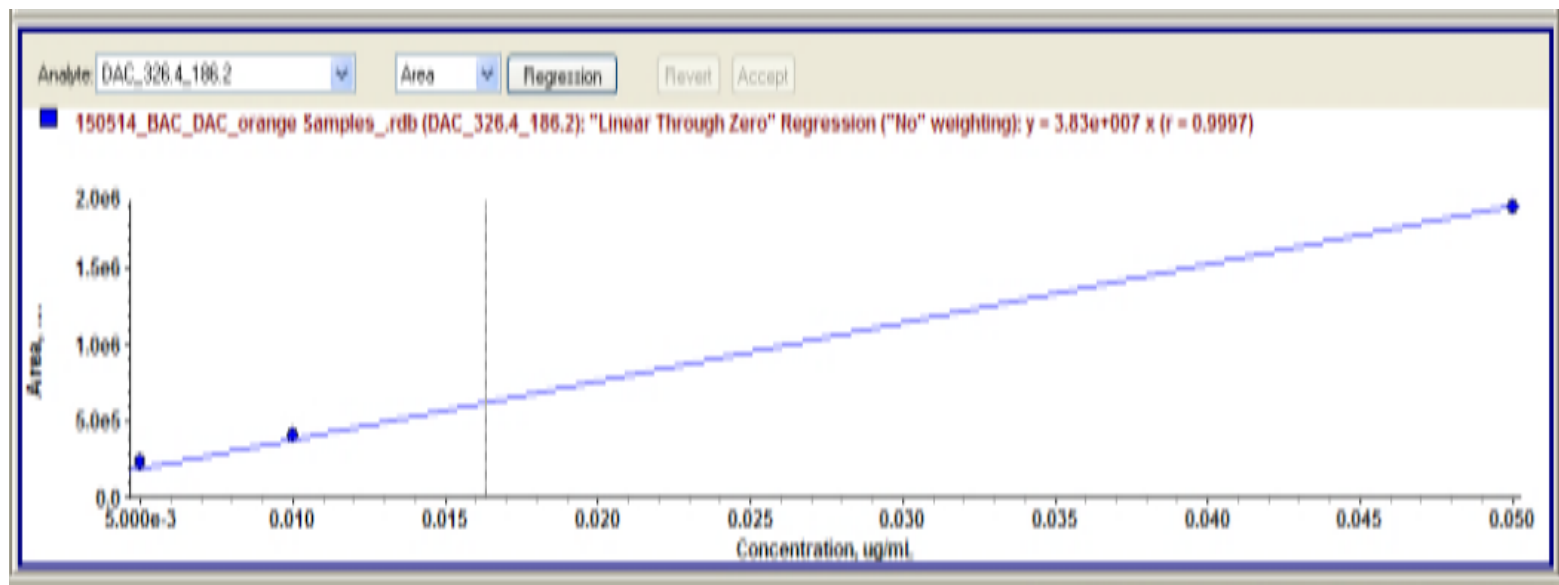

Fig. 5: DDAC calibration curve. 
Table (3): Regression coefficient (r) that represents the linearity of the calibration curve and also regression equation obtained for calibration.

\begin{tabular}{|l|c|c|}
\hline \multicolumn{1}{|c|}{ Compounds } & r & Regression equation \\
\hline DDAC_326.4_186.2 & 0.9997 & $\mathrm{Y}=3.83 \mathrm{e}+00^{7} *(\mathrm{r}=0.9997)$ \\
\hline BAC16_360_91 & 0.9998 & $\mathrm{Y}=3.57 \mathrm{e}+00^{7} *(\mathrm{r}=0.9998)$ \\
\hline BAC12_304_91 & 1.0000 & $\mathrm{Y}=4.38 \mathrm{e}+00^{7} *(\mathrm{r}=1.0000)$ \\
\hline BAC14_332.3_91 & 1.0000 & $\mathrm{Y}=6.03 \mathrm{e}+00^{7} *(\mathrm{r}=1.0000)$ \\
\hline BAC_10_276_184 & 0.9999 & $\mathrm{Y}=9.02 \mathrm{e}+00^{6} *(\mathrm{r}=0.9999)$ \\
\hline
\end{tabular}

Table (4): Mean recovery \% ( \pm RSD \%) of the QACs at different levels of fortifications $(n=6)$ for green beans, orange and olive.

\begin{tabular}{|c|c|c|c|c|c|c|c|c|c|}
\hline \multirow[t]{2}{*}{ Compound } & \multicolumn{3}{|c|}{$\begin{array}{c}\text { Green Beans } \\
\text { Mean } \pm \text { RSD\% }\end{array}$} & \multicolumn{3}{|c|}{$\begin{array}{c}\text { Orange } \\
\text { Mean } \pm \mathbf{R S D} \%\end{array}$} & \multicolumn{3}{|c|}{$\begin{array}{c}\text { Olive } \\
\text { Mean } \pm \text { RSD } \%\end{array}$} \\
\hline & $\begin{array}{c}0.01 \\
\mathrm{mg} / \mathrm{kg}\end{array}$ & $\begin{array}{c}0.05 \\
\mathrm{mg} / \mathrm{kg}\end{array}$ & $\begin{array}{c}0.1 \\
\mathrm{mg} / \mathrm{kg}\end{array}$ & $\begin{array}{c}0.01 \\
\mathrm{mg} / \mathrm{kg}\end{array}$ & $\begin{array}{c}0.05 \\
\mathrm{mg} / \mathrm{kg}\end{array}$ & $\begin{array}{c}0.1 \\
\mathrm{mg} / \mathrm{kg}\end{array}$ & $\begin{array}{c}0.01 \\
\mathrm{mg} / \mathrm{kg}\end{array}$ & $\begin{array}{c}0.05 \\
\mathrm{mg} / \mathrm{kg}\end{array}$ & $\begin{array}{c}0.1 \\
\mathrm{mg} / \mathrm{kg}\end{array}$ \\
\hline DDAC _326.4_186.2 & $83 \pm 9$ & $94 \pm 5$ & $93 \pm 5$ & $103 \pm 4$ & $98 \pm 3$ & $97 \pm 8$ & $90 \pm 8$ & $86 \pm 4$ & $110 \pm 4$ \\
\hline DDAC _326.4_43.2 & $80 \pm 8$ & $93 \pm 5$ & $95 \pm 6$ & $107 \pm 7$ & $97 \pm 3$ & $95 \pm 9$ & $78 \pm 7$ & $84 \pm 5$ & $105 \pm 9$ \\
\hline DDAC _326.4_41.2 & $89 \pm 8$ & $95 \pm 5$ & $94 \pm 5$ & $105 \pm 5$ & $97 \pm 3$ & $98 \pm 8$ & $93 \pm 8$ & $91 \pm 4$ & $109 \pm 8$ \\
\hline BAC16_360_91 & $84 \pm 10$ & $109 \pm 10$ & $109 \pm 4$ & $99 \pm 11$ & $86 \pm 4$ & $91 \pm 3$ & $92 \pm 6$ & $84 \pm 2$ & $89 \pm 1$ \\
\hline BAC16_360_268 & $88 \pm 4$ & $109 \pm 11$ & $110 \pm 5$ & $104 \pm 11$ & $86 \pm 4$ & $91 \pm 3$ & $85 \pm 6$ & $87 \pm 3$ & $98 \pm 3$ \\
\hline BAC12_304_91 & $87 \pm 6$ & $95 \pm 4$ & $90 \pm 5$ & $106 \pm 14$ & $96 \pm 3$ & $95 \pm 2$ & $97 \pm 8$ & $90 \pm 2$ & $104 \pm 5$ \\
\hline BAC12_304_212 & $86 \pm 6$ & $93 \pm 4$ & $91 \pm 5$ & $107 \pm 15$ & $97 \pm 3$ & $95 \pm 2$ & $100 \pm 8$ & $91 \pm 2$ & $114 \pm 7$ \\
\hline BAC14_332.3_91 & $83 \pm 8$ & $97 \pm 5$ & $93 \pm 5$ & $99 \pm 7$ & $97 \pm 4$ & $93 \pm 8$ & $96 \pm 8$ & $90 \pm 4$ & $116 \pm 4$ \\
\hline BAC14_332.3_240.3 & $83 \pm 8$ & $98 \pm 5$ & $92 \pm 5$ & $100 \pm 7$ & $97 \pm 4$ & $95 \pm 8$ & $92 \pm 8$ & $90 \pm 5$ & $108 \pm 9$ \\
\hline BAC14_332_91 & $83 \pm 11$ & $98 \pm 6$ & $95 \pm 5$ & $101 \pm 10$ & $94 \pm 3$ & $94 \pm 5$ & $80 \pm 10$ & $89 \pm 6$ & $93 \pm 8$ \\
\hline BAC_10_276_184 & $83 \pm 7$ & $93 \pm 4$ & $87 \pm 3$ & $104 \pm 12$ & $94 \pm 4$ & $94 \pm 10$ & $84 \pm 7$ & $89 \pm 2$ & $97 \pm 3$ \\
\hline BAC_10_276_91 & $98 \pm 6$ & $84 \pm 4$ & $98 \pm 8$ & $94 \pm 5$ & $91 \pm 3$ & $91 \pm 5$ & $86 \pm 8$ & $87 \pm 3$ & $117 \pm 5$ \\
\hline
\end{tabular}

Table (5): Standard deviation (SD) and LOD $(\mu \mathrm{g} / \mathrm{kg})$ of the QACs for green beans, orange and olive.

\begin{tabular}{|l|c|c|c|c|c|c|}
\hline \multirow{2}{*}{ Compound } & \multicolumn{2}{|c|}{ Green beans } & \multicolumn{2}{c|}{ Orange } & \multicolumn{2}{c|}{ Olive } \\
\cline { 2 - 7 } & SD & $\begin{array}{c}\text { LOD } \\
\text { (mg/kg) }\end{array}$ & SD & $\begin{array}{c}\text { LOD } \\
(\mathbf{m g} / \mathbf{k g})\end{array}$ & SD & $\begin{array}{c}\text { LOD } \\
\text { (mg/kg) }\end{array}$ \\
\hline DDAC_326.4_186.2 & 0.000894 & $\mathbf{0 . 0 0 3}$ & 0.000516 & $\mathbf{0 . 0 0 2}$ & 0.000923 & $\mathbf{0 . 0 0 3}$ \\
\hline DDAC_326.4_43.2 & 0.000813 & $\mathbf{0 . 0 0 2}$ & 0.000905 & $\mathbf{0 . 0 0 3}$ & 0.000754 & $\mathbf{0 . 0 0 2}$ \\
\hline DDAC_326.4_41.2 & 0.000825 & $\mathbf{0 . 0 0 2}$ & 0.000609 & $\mathbf{0 . 0 0 2}$ & 0.000918 & $\mathbf{0 . 0 0 3}$ \\
\hline BAC16_360_91 & 0.000833 & $\mathbf{0 . 0 0 2}$ & 0.001124 & $\mathbf{0 . 0 0 3}$ & 0.000597 & $\mathbf{0 . 0 0 2}$ \\
\hline BAC16_360_268 & 0.000368 & $\mathbf{0 . 0 0 1}$ & 0.001154 & $\mathbf{0 . 0 0 3}$ & 0.000655 & $\mathbf{0 . 0 0 2}$ \\
\hline BAC12_304_91 & 0.000497 & $\mathbf{0 . 0 0 1}$ & 0.001344 & $\mathbf{0 . 0 0 4}$ & 0.001026 & $\mathbf{0 . 0 0 3}$ \\
\hline BAC12_304_212 & 0.000458 & $\mathbf{0 . 0 0 1}$ & 0.001407 & $\mathbf{0 . 0 0 4}$ & 0.000953 & $\mathbf{0 . 0 0 3}$ \\
\hline BAC14_332.3_91 & 0.000819 & $\mathbf{0 . 0 0 2}$ & 0.000799 & $\mathbf{0 . 0 0 2}$ & 0.000956 & $\mathbf{0 . 0 0 3}$ \\
\hline BAC14_332.3_240.3 & 0.000755 & $\mathbf{0 . 0 0 2}$ & 0.000854 & $\mathbf{0 . 0 0 3}$ & 0.000926 & $\mathbf{0 . 0 0 3}$ \\
\hline BAC14_332_91 & 0.001032 & $\mathbf{0 . 0 0 3}$ & 0.001023 & $\mathbf{0 . 0 0 3}$ & 0.0011 & $\mathbf{0 . 0 0 3}$ \\
\hline BAC_10_276_184 & 0.000533 & $\mathbf{0 . 0 0 2}$ & 0.000798 & $\mathbf{0 . 0 0 2}$ & 0.000631 & $\mathbf{0 . 0 0 2}$ \\
\hline BAC_10_276_91 & 0.000652 & $\mathbf{0 . 0 0 2}$ & 0.000322 & $\mathbf{0 . 0 0 1}$ & 0.000732 & $\mathbf{0 . 0 0 2}$ \\
\hline
\end{tabular}




\section{Limit of quantification (LOQ)}

The minimum concentration or mass of the analyte that could quantify with acceptable accuracy and precision was determined to be $0.01 \mathrm{mg} / \mathrm{kg}$.

The analyte is considered quantitative when their abundance confirmation ion signal to noise is $\mathrm{S} / \mathrm{N} \geq 3$ with an accurate quantitation of $\pm 20 \%$ of their true value in the calibration standard.

Sample residues that met all criteria but had $\mathrm{S} / \mathrm{N}<3$ were reported as less than the limit of quantification $(<\mathrm{LOQ})$, while those which had not fit any criteria were reported as not detected (N.D).

\section{Accuracy}

It is performed by measuring both "Trueness" and "Precision" of the validated method.

The precision of the method including measuring of the repeatability where the definition of repeatability refers to a single analyte in any practical context the definition will be understood the assumption that all the analysts who carry out the analysis are fully trained to extent of achieving a uniform level of precision. With the assumption, a combined standard deviation based on the data from the three levels of concentrations provides a realistic estimate of the level of repeatability precision that is being achieved routinely in the laboratory.

The accuracy is measured by calculating Z-score for found concentration of target compounds by participating in method proficiency test by FAPAS and European commission.

Where Z-score is a statistical measure that quantifies the distance (measured in standard deviations) a data point is from the mean of a data set. Where Z-score could be calculated using the following equation:

$$
\mathrm{Z}=\frac{|\mathrm{X}-\mathrm{Xi}|}{\mathrm{S}}
$$

Where $\mathrm{X}$ is the found concentration,

$\mathrm{Xi}$ is the assigned value,

$\mathrm{S}$ is the standard deviation of set of results.

Table (6) shows the results of method proficiency test by FAPAS®Report 19196 for Salad leaves (September 2015) and Table (7) shows the results of method proficiency test by EUPT-SRM11, June 2016 for Spinach homogenate.

\section{Precision (including repeatability and within- laboratory reproducibility)}

In this study intra-laboratory, reproducibility was considered, by spiking the samples analyzed by different analysts on several days.

\section{Reproducibility}

It is defined as conditions where test results are obtained with the same method on identical test items in different laboratories with different operators using different equipment within laboratory, reproducibility was estimated from validation data by pooling the variances of the different levels ${ }^{[18]}$ as shown in Table (8).

$\mathrm{QR}_{\text {typ }}=$ the average recovery of the three levels of concentration.

$$
R S D_{\text {pooikd }}=\sqrt{\frac{\left(R S D_{1}^{2}\left(n_{1}-1\right)+\left(R S D_{2}^{2}(n 2-1)+\ldots \ldots\right.\right.}{\left(n_{1}-1\right)+\left(n_{2}-1\right)+\ldots .}}
$$

$\mathrm{RSD}=$ Relative standard deviation.

$\mathrm{n}_{1}=$ number of samples for concentration level 0.01 $\mathrm{mg} / \mathrm{kg}$ and $\mathrm{n}_{2}$ for concentration level $0.05 \mathrm{mg} / \mathrm{kg}$.

$\mathrm{RSD}_{1}$ is the relative standard deviation of concentration level $0.01 \mathrm{mg} / \mathrm{kg}$ and $\mathrm{RSD}_{2}$ for concentration level 0.05 $\mathrm{mg} / \mathrm{kg}$.

The reported results in Table (8) for pooled RSD provide evidence that the adapted QuEChERS method achieved for most of the QACs give good recoveries, repeatability, and reproducibility.

Most of the RSD's for QACs in the three validation levels for green beans, orange and olive were in the range lower than $15 \%$ indication accepted repeatability and reproducibility of the method.

\section{Measurement uncertainty (MU)}

Uncertainty is a parameter associated with the results of a measurement that characterizes the dispersion of the values that could reasonably be attributed to the measuring. Euachem guidelines were followed to estimate $\mathrm{MU}^{[19]}$.

Combined uncertainty $\left(\mathrm{U}_{\mathrm{c}}\right)$ was found to be $9.3,9.5$ and $8.9 \%$ for green beans, orange and olive, respectively. The following equation was used for combined uncertainty calculations:

$$
U_{C}=\sqrt{\left(U_{p}\right)^{2}+\left(U_{\operatorname{Re} c}\right)^{2}+U_{\operatorname{Re} f}}
$$

$\mathrm{U}_{\mathrm{p}}$ is the relative standard uncertainty due to precision experiments expressed as relative standard deviation was found to be less than $15 \%$ (the highest RSD pooled for BAC16) was found $9 \%$ in green beans, while in orange was found $9 \%$ for $\mathrm{BAC} 12$ and $\mathrm{BAC} 10$ and in olive is $8 \%$ for $\mathrm{BAC} 14, \mathrm{U}_{\mathrm{Rec}}$ is the relative standard uncertainty was calculated as the standard deviation of the mean using the following equation:

$$
\mathrm{U}_{\mathrm{Rec}}=\frac{\mathrm{s}}{\sqrt{\mathrm{n}}}
$$

Where $\mathrm{s}$ is standard deviation and $\mathrm{n}$ is the number of samples.

$\mathrm{U}_{\mathrm{Ref}}$ is the uncertainty component due to reference standard preparation was found to be $0.7 \%$.

Expanded uncertainty was obtained by multiplying the combined uncertainty, by a coverage factor $\mathrm{k}$, for confidence level of $95 \% \mathrm{k}$ is 2 .

Therefore, when a traceable measurement $\mathrm{x}$ is made, it is reported with its associated expanded measurement uncertainty as $\mathrm{x} \pm \mathrm{U}_{\mathrm{k}=2}$ where $\mathrm{U}_{\mathrm{k}}$ is Expanded uncertainty at confidence interval $90 \%$.

\section{Conclusion}

The optimized method is rapid, reliable and precise that could be applied to monitor QACs in green beans, orange, olive and other agricultural products in order to submit them to local or international markets. 
Table (6): Results of method proficiency test by FAPAS®Report 19196 for Salad leaves (September 2015).

\begin{tabular}{|c|c|c|c|c|}
\hline Compound & $\begin{array}{c}\text { Found } \\
(\mathbf{m g} / \mathbf{k g})\end{array}$ & $\begin{array}{c}\text { Assigned value } \\
(\mathbf{m g} / \mathbf{k g})\end{array}$ & $\begin{array}{c}\mathbf{S} \\
\text { (standard deviation) }\end{array}$ & Z-score* \\
\hline BAC14 & 0.304 & 0.306 & 58.5 & $\mathbf{0 . 2 9 9}$ \\
\hline BAC16 & 0.30 & 0.258 & 50.7 & $\mathbf{0 . 2 9 5}$ \\
\hline
\end{tabular}

Table (7): Results of method proficiency test by EUPT-SRM11, June 2016 for Spinach homogenate.

\begin{tabular}{|c|c|c|c|c|}
\hline Compound & $\begin{array}{c}\text { Found } \\
(\mathbf{m g} / \mathbf{k g})\end{array}$ & $\begin{array}{c}\text { Assigned value } \\
(\mathbf{m g} / \mathbf{k g})\end{array}$ & $\begin{array}{c}\text { S } \\
\text { (standard deviation) }\end{array}$ & Z-score* \\
\hline BAC14 & 0.290 & 0.284 & 0.06 & $\mathbf{0 . 1}$ \\
\hline
\end{tabular}

Table (8): Relative standard deviation pooled standard deviation and the average Recovery of the three levels of concentrations for green beans, orange and olive.

\begin{tabular}{|c|c|c|c|c|c|c|}
\hline \multirow[b]{2}{*}{ Compound } & \multicolumn{2}{|c|}{ Green beans } & \multicolumn{2}{|c|}{ Orange } & \multicolumn{2}{|c|}{ Olive } \\
\hline & $\begin{array}{l}. R \\
T y p \% \\
\end{array}$ & $\begin{array}{c}R S D \\
\text { pooled\% }\end{array}$ & $\begin{array}{l}\text { Q.R } \\
\text { Typ\% }\end{array}$ & $\begin{array}{l}\text { RSD } \\
\text { pooled\% }\end{array}$ & $\begin{array}{l}Q . R \\
T y p \% \\
\end{array}$ & $\begin{array}{c}R S D \\
\text { pooled } \%\end{array}$ \\
\hline DDAC_326.4_186.2 & 90 & 7 & 99 & 6 & 95 & 6 \\
\hline DDAC_326.4_43.2 & 89 & 6 & 100 & 7 & 89 & 7 \\
\hline DDAC_326.4_41.2 & 93 & 6 & 100 & 6 & 97 & 7 \\
\hline BAC16_360_91 & 101 & 9 & 92 & 7 & 88 & 4 \\
\hline BAC16_360_268 & 102 & 7 & 94 & 7 & 90 & 4 \\
\hline BAC12_304_91 & 91 & 5 & 99 & 8 & 97 & 6 \\
\hline BAC12_304_212 & 90 & 5 & 99 & 9 & 102 & 6 \\
\hline BAC14_332.3_91 & 91 & 7 & 96 & 6 & 101 & 6 \\
\hline BAC14_332.3_240.3 & 91 & 6 & 97 & 7 & 97 & 7 \\
\hline BAC14_332_91 & 92 & 8 & 96 & 7 & 87 & 8 \\
\hline BAC_10_276_184 & 88 & 5 & 97 & 9 & 90 & 5 \\
\hline BAC_10_276_91 & 93 & 6 & 92 & 4 & 97 & 5 \\
\hline
\end{tabular}

\section{References}

1) Richards, R. M. and Xing, D. K. (1993). In vitro evaluation of the antimicrobial activities of selected lozenges. J. Pharm. Sci., 82(12):1218-1220.

2) Matthew, J. S. and Malcolm, N. J. (2000). The biodegradation of surfactants in the environment. Journal of Biochimicaet Biophysica Acta (BBA) Biomembranes, 1508(1-2):235-251.

3) Leal, J. S., Gonzalez, J. J., Kaiser-KLE, Palabrica, V. S., Comelles, F. and Garcia, M. T. (1994). Toxicity and biodegradation of cationic surfactants. Journal of Acta Hydrochim Hydrobiol, 22(1):13-18.

4) Merck, Merck Index, 13th ed., Whitehouse station, Merck Research Laboratories, (2001), p. 1060.
5) Gomez-Gomar, A., Gonzalez-Aubert, M. M., Garces-Torrents, J. and Costa-Segarra, J. (1990). Determination of benzalkonium chloride in aqueous ophthalmic preparations by high-performance liquid chromatography. J. Pharm. Biomed. Anal., 8(812):871-876.

6) Merianos J. J. (1991). Quaternary ammonium antimicrobial compounds disinfection, sterilization and preservation.In: Block SS, editor. 4th ed. Philadelphia: Lea \& Febiger; p. 225-225. http://trove.nla.gov.au/version/45736191

7) European Food Safety Authority (2013). Evaluation of monitoring data on residues of didecyldimethylammonium chloride (DDAC) and benzalkonium chloride (BAC). EFSA Journal, 10(2):1-24. DOI: 10.2903/sp.efsa.2013.EN-483 
8) Ferrer, I. and Furlong, E. (2001). Identification of alkyl dimethylbenzylammonium surfactants in water samples by solid-phase extraction followed by ion trap LC/MS and LC/MS/MS. J. Environ. Sci. Technol., 35(12):2583-2588.

9) Núñez, O., Moyano, E. and Galceran, M. (2004). Determination of quaternary ammonium biocides by liquid chromatography-mass spectrometry. Journal of Chromatography A, 1058(1-2):89-95.

10) Mehta, J., Patidar, K. and Vyas, N. (2010). Development and validation of a precise method for determination of benzalkonium chloride (BKC) preservative, in pharmaceutical formulation of latanoprost eye drops. E. J. Chem., 7:11-20.

11) Bassarab, P., Williams, D., Dean, J. R., Ludkin, E. and Perry, J. J. (2011). Determination of quaternary ammonium compounds in seawater samples by solid-phase extraction and liquid chromatography-mass spectrometry. Journal of Chromatography A, 1218(5):673-677.

12) Patel, P., Varshney, P., Patel, D. and Meshram, D. (2014). Method Development and Validation of Benzalkonium Chloride in Marketed Formulation By UV-Visible Spectrophotometry Using Silver Nitrate. World J. Pharm. and Pharm. Sci., 3(2):1481-1487.
13) Codex Alimentarius Commission (1993). Portion of Commodities to which Codex Maximum Residue Limits Apply and which is analyzed. Vol. 2, 2nd ed, section A, page 391-404.

14) European Committee for Standardization, (E. C. S.): Technical Committee 275 (Standards under development) Foods of plant origin, EN 15662 (2008). Determination of pesticide residues using GC-MS and/or LC-MS/MS) following acetonitrile extraction/partitioning and cleanup by dispersive SPE- QuEChERS method. Brussels.

15) Codex Guidelines on Good Laboratory Practice in Residue Analysis (1998). (Alinorm 03/24A) Appendix II, pages 46-79.

16) CITAC/Eurachem Guide (2002). Guide to Quality in Analytical Chemistry, an aid to accreditation.

17) Eurachem guidelines (1998). The Fitness for Purpose of Analytical Methods A Laboratory Guide to Method Validation and Related Topics. Second Edition 2014, Pages 8-37.

18) Prudnikov, E. D. (1981). J. Spect. Chim. Acta., 36(4):385-392.

19) Eurachem guidelines (1998). The Fitness for Purpose of Analytical Methods A Laboratory Guide to Method Validation and Related Topics. Second Edition 2014, Pages 38-42. 